Instructions for authors, subscriptions and further details:

http://ijep.hipatiapress.com

\title{
Mindfulness as an Alternative for Supporting University Student Mental Health: Cognitive-Emotional and Depressive Self- Criticism Measures
}

Muhammad Abid Azam, Myriam Mongrain, Khushboo Vora, Meysam Pirbaglou, Saam Azargive, Tina Changoor, Noah Wayne, Crissa Guglietti, Alison Macpherson, Jane Irvine, Michael Rotondi, Dawn Smith, Daniel Perez, Paul Ritvo ${ }^{1}$

1) York University

Date of publication: June $24^{\text {th }}, 2016$

Edition period: June 2016 - October 2016

To cite this article: Azam et al. (2016). Mindfulness as an alternative for supporting university student mental health: cognitive-emotional and depressive self-criticism measures. International Journal of Educational Psychology, 5(2), 140-163. doi: 10.17583/ijep.2016.1504

To link this article: http://dx.doi.org/10.17583/ijep.2016.1504

\section{PLEASE SCROLL DOWN FOR ARTICLE}

The terms and conditions of use are related to the Open Journal System and to Creative Commons Attribution License (CC-BY). 


\section{Mindfulness as an Alternative for Supporting University Student Mental Health: Cognitive- Emotional and Depressive Self- Criticism Measures}

Muhammad Abid Azam, Myriam Mongrain, Khushboo Vora, Meysam Pirbaglou, Saam Azargive, Tina Changoor, Noah Wayne, Crissa Guglietti, Alison Macpherson, Jane Irvine, Michael Rotondi, Dawn Smith, Daniel Perez, Paul Ritvo ${ }^{1}$

York University

\section{Abstract}

Increases in university-based mental health problems require alternative mental health programs, applicable to students with elevated psychological risks due to personality traits. This study examined the cognitive-emotional outcomes of a university mindfulness meditation (MM) program and their relationship with Self-Criticism (SC), a personality factor linked to depressive vulnerability. University students $(n=71)$ were assessed at baseline with the Depressive Experiences Questionnaire (DEQ), a measure of depressive personality traits, and two outcome measures: Profile of Mood States (POMS) and Anxiety Sensitivity Index (ASI). Students attending the MM program were reassessed for outcomes at 3 follow up assessments over 2 semesters. Repeated measures analyses of variance revealed improved within-subjects effects with large or very large effect sizes for the subsample that completed the MM program $(n=18)$ on the POMS Tension-Anxiety, POMS Depression, POMS Fatigue, and Anxiety Sensitivity Index. Multiple linear regression using self-criticism as a predictor of change in depressed mood revealed that higher self-criticism predicted greater reductions in POMS Depression. This study provides evidence for MM-related cognitiveemotional benefits, suggesting that students with elevated self-critical traits may derive exceptional benefits evident in greater reductions of depressed mood.

Keywords: mindfulness, meditation, mental health, university students, depression 


\section{Mindfulness una Alternativa de Apoyo a la Salud Mental del Alumnado Universitario: Medidas Cognitivo-Emocionales y de Autocrítica Depresiva}

Muhammad Abid Azam, Myriam Mongrain, Khushboo Vora, Meysam Pirbaglou, Saam Azargive, Tina Changoor, Noah Wayne, Crissa Guglietti, Alison Macpherson, Jane Irvine, Michael Rotondi, Dawn Smith, Daniel Perez, Paul Ritvo ${ }^{1}$ York University

\section{Resumen}

Este estudio examinó los resultados cognitivos y emocionales de un programa de meditación de atención plena (MAP) en una universidad en relación a la autocrítica, un factor de la personalidad vinculado con la vulnerabilidad depresiva. 71 estudiantes universitarios fueron evaluados al inicio del estudio con el Cuestionario de las Experiencias Depresivas, una medida de los rasgos de la personalidad depresiva, y dos medidas de resultado: el Perfil de los Estados de Ánimo (POMS) y el Índice de Sensibilidad a la Ansiedad. Los estudiantes que asistieron al programa MAP fueron reevaluados para los resultados en 3 seguimientos de evaluación durante 2 semestres. Medidas repetidas ANOVA reveló efectos mejorados intrasujetos con grandes o muy grandes tamaños del efecto para la sub-muestra que completó el programa MAP ( $\mathrm{n}=18$ ); POMS tensión-Ansiedad, Depresión POMS, POMS fatiga y Índice de sensibilidad ansiedad. La regresión lineal múltiple utilizando la autocrítica como predictor de cambio en el estado de ánimo deprimido reveló que una autocrítica mayor predijo mayores reducciones en POMS Depresión. Este estudio proporciona evidencia de beneficios cognitivos emocionales relacionadas con el MAP, e indica que los estudiantes con rasgos autocríticas elevados pueden derivar beneficios excepcionales evidentes en mayores reducciones de estado de ánimo deprimido.

Palabras clave: mindfulness, meditación, salud mental, universitarios, depresión 
According to the National College Health Assessment, half of university students report above-average to high levels of 1 psychological distress, with the assessed prevalence of anxiety and depressive disorders increasing from $20 \%$ to $24 \%$, in just the last five years (ACHA, 2013). Student distress is exacerbated by inadequate studentcounselor ratios (Lees \& Davis, 2012), help-seeking barriers, and subclinical stress conditions, and mental health risk-elevating personality traits (e.g. maladaptive perfectionism) (Radhu, Daskalakis, Arpin-Cribbie, Irvine, \& Ritvo, 2012) that can progress to diagnosable psychopathology if not preventively counteracted.

A longitudinal study of 16, 460 first-year undergraduate students in the United Kingdom showed steadily increasing depression and anxiety scores over the progressive course of their time in university academic programs (Cooke, Bewick, Barkham, Bradley, \& Audin, 2006). Recent estimates indicate one-third of university students experience depressed-anxious moods (Eisenberg, Gollust, Golberstein, \& Hefner, 2007) and one-quarter display maladaptive perfectionism (Radhu et al., 2012). The increasing rates and complexities of mental health disturbances have strained traditional university counseling resources (Lees \& Davis, 2012), with cumulative data indicating a need for alternative mental health programs that would address the large numbers of students who fail to receive adequate support via traditional counselling. Furthermore, such programs could respond to recent data showing students prefer dealing with stress-related issues autonomously (73.3\%) and believe they lack sufficient time for counseling treatment (46.7\%) (Downs \& Eisenberg, 2012)

\section{Mindfulness Meditation and Mental Health Benefits}

Scientific evidence is accumulating for the effectiveness of mindfulness meditation (MM) in treatment of anxiety-depressive disorders and reduction of distress. In MM research, individuals with self-critical tendencies are of particular interest, given their susceptibility to elevated stress (Grossman, Niemann, Schmidt, \& Walach, 2004) which can be mitigated by addressing and reducing their experiences of symptomatic depression and anxiety (Hazlett-Stevens, 2012). One of the purposes of our research was to examine 
the relationship between self-critical personality traits and improvements in psychological status in university students during MM program participation.

Mindfulness has been defined as increased awareness attained through deliberate, nonjudgmental attention to present time-frame experience (Didonna, 2009). During MM, participants attend to breathing sensations, and return attention to breathing after monitoring thoughts, emotions, and external stimuli. Attention to breathing sensations has several purposes: it orients one to a present time-frame, generates a relaxation effect, and can be readily resumed after distractive mind wandering (Grossman et al., 2004). With consistent practice, awareness of present-oriented experiences combined with a nonjudgmental attitude towards internal experiences, can reduce distress (Nyklícek \& Kuijpers, 2008). Furthermore, current research suggests regular MM improves the neurophysiological health of cortical areas associated with attention and emotion regulation (Lazar et al., 2006).

\section{Mindfulness and Depressive Self-Criticism}

As MM has emerged as a potentially cost-effective mental health intervention, investigators have placed special focus on how it impacts depression. Psychometric data on trait features of mindfulness suggest protection against specific depressive symptoms (Grossman et al., 2004) while evidence from intervention research indicates implementation of Mindfulness-Based Cognitive Therapy (MBCT) helps reduce depressive symptoms and prevents relapse to diagnosable depressive disorder (Chiesa $\&$ Serretti, 2011). To date, minimal research has focused on how depressive personality vulnerabilities affect students undergoing MM training. To address this gap, our study focused on examining MM effectiveness while examining student's depressive vulnerabilities as indicated by a wellestablished personality questionnaire. This screening instrument, the Depressive Experiences Questionnaire (DEQ), is a measure of depressive personality style reflecting trait-like patterns predictive of subsequent incidence of diagnosable depression. The scale is comprised of three factors: Self-Criticism (defined as a failure in meeting standards, feelings of inferiority, and decreased self-worth), Dependency (reliance on interpersonal 
relationships), and Efficacy (characterized by resilience in response to personal challenges) (Blatt, Zohar, Quinlan, Zuroff, \& Mongrain, 1995). In previous validation efforts, a 12-month study found the Self-Criticism (SC) subscale predicted periods of depressive distress, particularly concerning autonomy and self-esteem (Viglione, Lovette, Gottlieb, \& Friedberg, 1995).

The academic environment triggers self-critical states through frequent exposures to social-evaluative events. A past study revealed that negative automatic thoughts and anxiety sensitivity (i.e. fear of anxiety symptoms) mediated associations between symptoms of depression and anxiety (Pirbaglou et al., 2013). Theoretically, depressive self-criticism can be considered a trait manifestation of negative automatic thoughts, given the common characteristic of self-directed negative cognitive content. Selfcritical personality vulnerabilities are, overall, highly relevant to student populations and therefore important to examine in better understanding the potential targets of preventive mental health interventions like MM.

Recently, a study explored the Big-Five personality traits and MM practice (van den Hurk et al., 2011) using a cross-sectional design. Experienced meditators and control subjects (meditators $=35$, nonmeditators; 35) were compared and those who meditated demonstrated positive associations with curiosity and positive affect, as well as negative associations with worry (van den Hurk et al., 2011). A randomized controlled trial recently found evidence for the effectiveness of an 8-week MM program in lowering stress in college students (Oman, Shapiro, Thoresen, Plante, \& Flinders, 2008). Taken together, it seems the demanding and stress-inducing nature of the university environment is now well established, as are the mental health benefits of practicing MM. Accordingly, we were interested in implementing a low-cost, easily accessible MM training program within the university and evaluating its effectiveness.

The current paper extends prior research by examining the effectiveness of a specific MM training program designed for university students and exploring how students with self-critical traits. Our objectives were: i) to study changes in anxiety sensitivity and mood during the school year as students attended ongoing MM tutorials; ii) to study the relationship between self-critical traits and MM benefits over a two semester duration. 
The paper reports on changes in mood and anxiety sensitivity before, during, and after an MM program and the predictive associations between Self Critical trait levels (at baseline) \& depressed mood (at follow up). Participants were trained in MM over two continuous semesters, and two specific hypotheses guided evaluations:

(a) Participants will report progressive improvements in psychological well-being as measured by mood and anxiety sensitivity variables, reflecting MM effectiveness.

(b) Increased levels of Self-Criticism will predict greater reductions in depressed mood, reflecting the effectiveness of MM for those with markedly elevated Self-Critical personality traits. (This could also be understood via the corollary whereby lower levels of SC predict lesser reductions in depressed mood, following the premise that MM should have specific SC effects).

\section{Methods}

\section{Participants}

Seventy-one undergraduate students (43 females, 28 males) in a large public urban university participated in weekly MM sessions through the Fall and Winter semesters of the 2012/2013 academic year (Figure 1). Recruitment was facilitated through in-class announcements and poster-print advertisement. Online and paper surveys elicited self-report data reflecting mental health profiles at program initiation (baseline measures). Given the pragmatic study focus, the inclusion criteria were minimized: 1) currently enrolled in the university (part-time or full-time); and 2) computer access and/or smartphone access. Using a within-subjects design, participants were required to attend one MM tutorial per week during each semester and complete the psychological measures at three assessment periods; Time 2 (November- December), Time 3 (January-February), and Time 4 (MarchApril). To lessen participation demands on the students, follow-up assessments were provided in paper and electronic formats as needed. All 
data were anonymized and maintained in a locked cabinet within a locked, secure office to ensure confidentiality. Study participants were given $\$ 50$ cash payments for full study participation. This study met ethical guidelines and was approved by the Human Participants Review Subcommittee at York University where the study was conducted.

\section{Intervention}

The program progressively trained students in "mindfulness of breathing", a form of meditation frequently employed secularly (Didonna, 2009). Meditation tutorials were held on campus five times weekly, led by a faculty member and graduate students who were trained and experienced MM practitioners. The MM instruction standardly used guided participants to be seated on a chair or on the floor in a comfortable, attentive posture, free to close their eyes or keep them open. They were instructed to pay attention to breathing sensations and to mind-wandering events in a nonjudgmental manner. Tutorial leaders were provided ongoing supervision and training that combined investigations about their own MM experiences with explorations and feedback about the provision of verbal guidance to students during sessions. The tutorials were one hour in duration and typically involved 40-45 minutes of guided MM followed by a question-answer period based on participant experiences during and outside of the MM tutorials. Program participation required attendance at one tutorial per week, and participants were encouraged to conduct additional informal, independent MM practice.

\section{Predictor Variable}

Depressive Experiences Questionnaire (DEQ) (Viglione et al., 1995). This 66-item questionnaire assesses levels of Self-Criticism and Dependency through a 7-point Likert scale ranging from 1 (strongly disagree) to 7 (strongly agree). Dependency is characterized by submissiveness in interpersonal relationships and an intense desire for closeness coupled with fear of rejection while Self-Criticism, the measure emphasized in the current study, is defined by feelings of inferiority, guilt, and worthlessness, and 
related to a sense of failure in meeting standards and expectations (Fuhr \& Shean, 1992). Test-retest reliabilities for the DEQ factors are high, with testretest correlations of .86 over a 3-4 week interval, .72 - .81 after a 13-week interval and of .79 for Dependency and Self- Criticism after a 1-year interval (Fuhr \& Shean, 1992). Alpha coefficients have been previously calculated as .80 for Self-Criticism, and construct validity has been evidenced in a variety of contexts (Viglione et al., 1995). The DEQ was administered through the baseline survey, and standardized scores of selfcriticism were calculated for each participant.

\section{Outcome Variables}

Profile of Mood States (POMS) (Bourgeois, LeUnes, \& Meyers, 2010). The POMS is an adjective-based rating scale used to assess mood state and mood changes. It includes five negative mood subscales of Tension-Anxiety, Depression-Dejection, Fatigue-Inertia, Anger-Hostility, and ConfusionBewilderment, and one positive mood subscale (Vigour-Activated). This study used a short 38-item version (Baker, Denniston, Zabora, Polland, \& Dudley, 2002), and analyses focused on individual scores on the TensionAnxiety (e.g., "Nervous"), Depression (e.g. "Discouraged") and Fatigue (e.g., "Worn Out") subscales. The alpha coefficients for Tension-Anxiety, Depression, and Fatigue have been found to be 0.79, 0.90, and 0.90 respectively (Bourgeois et al., 2010). Participants were asked to respond to the items based on how they felt at the time of questionnaire completion.

Anxiety Sensitivity Index (ASI) (Reiss, Peterson, Gursky, \& McNally, 1986). The ASI is a 16-item inventory in which a 5-point Likert-based scale is used to rate the degree of concern about negative consequences of anxietyrelated sensations. Anxiety sensitivity (AS) refers to a set of beliefs that physical anxiety symptoms have negative effects such as causing more severe distress, development of major illness, or socially detrimental consequences (Reiss et al., 1986). As the most widely validated established index of AS, the ASI has been found to have a factorial structure (Rodriguez, Bruce, Pagano, \& Keller, 2004) that measures 3 factors: physical concerns ("It scares me when my heart beats rapidly"), mental incapacitation concerns ("When I can't keep my mind on a task, I worry that 
I might be going crazy"), and fears of publicly observable anxiety reactions ("Other people notice when I feel shaky"). In this study, total ASI score was used to measure AS, as it represents the global-order anxiety sensitivity factor and therefore reflects cognitive-emotional processes related to anxious arousal (Rodriguez et al., 2004).

\section{Statistical Analysis}

We conducted repeated measures ANOVA to assess the effect of MM program over the study period (Table 2) in the subsample that completed all measures. These included pairwise tests between baseline measurements and scores obtained at the three subsequent time points. To capitalize on the relatively large sample available at Time $2(n=37)$, correlational analyses assessed the relationships between SC and POMS Depression in this subsample who underwent a full semester of MM training. The correlations between SC and POMS Depression were assessed at baseline, and SC and change scores were assessed at Time 2, with change scores calculated at each stage in reference to baseline measurements by subtracting scores at each time point from baseline scores. Change scores are referred to in the results section with the 'delta' symbol ( $\triangle$ POMS Depression Time 2). Furthermore, as differing data were available at each assessment period due to participant attrition, we tested whether $\mathrm{SC}$ was associated with attrition using an independent samples t-test to explore SC effects. Finally, using multiple linear regression analyses, we assessed whether the significant relationships observed in the correlational analyses remained significant after controlling for potential confounding variables (Table 3). We used G*Power 3.1 (Erdfelder, Lang, \& Buchner, 2007) to calculate post-hoc (observed) power for all ANOVA and regression models and SPSS statistical software (IBM Corp., 2011) for analytic procedures.

\section{Results}

\section{Participation}

For ethical, health and practical reasons, participants and interested students were permitted to attend MM tutorials regardless of participation in research 
activities. Of the initial 71 students, $25.3 \%(n=18)$ completed all four assessments (Figure 1). In addition, another 10 participants ceased completing questionnaires at various points but continued participation in meditation activities for the full duration of the study. Participants who dropped out and responded to inquiries most commonly cited workload or scheduling conflicts as reasons for ending participation, on a purely anecdotal basis.

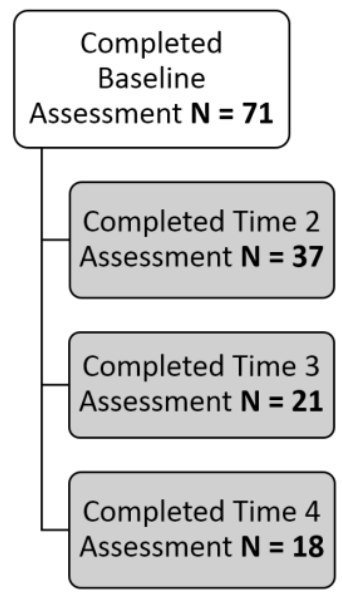

Figure 1: Completion of Assessments for Attending Mindfulness Meditation Program during the School Year. Flow chart of number of participants completing assessments throughout the MM program.

Participant attrition was a key study challenge which we believe is explained by multiple factors. The nature of the participant pool as individuals at elevated risk for anxiety, depression, and high sensitivity to critical thoughts (see baseline psychometric results) makes them more likely sensitive to academic pressures and university life stressors in ways than the general university student population. Particular evidence of their stress vulnerability was found in the high levels of drop-out surrounding the Fall examination period, as students studied for exams and completed final assignments critical to final grades. While the participants who remained 
until the end of study were sufficient in number to conduct meaningful statistical analyses, the impact of attrition on the validity of these findings for those unable to persist with intervention and study assessments is acknowledged.

Table 1:

Baseline Demographics

\begin{tabular}{lcc}
\hline Demographic Variable & Frequency & Percentage (\%) \\
\hline Total Recruited & 71 & -- \\
Age $(\mu=25.5 ; \sigma=10.17)$ & & \\
$18-20$ & 23 & 34.3 \\
$21-23$ & 26 & 38.8 \\
$>24$ & 18 & 26.9 \\
Missing & 4 & .056 \\
Gender & & \\
Female & 43 & 66.2 \\
Male & 22 & 33.8 \\
Missing & 6 & .085 \\
Ethnicity & 2 & \\
West Asian & 5 & 3.1 \\
Black - African & 4 & 7.7 \\
Black/Indo - Caribbean & 28 & 6.1 \\
Caucasian & 2 & 43.1 \\
Latin American/Hispanic & 9 & 3.1 \\
Oriental (Chinese, Korean) & 10 & 13.8 \\
South Asian & 5 & 6.5 \\
South East Asian & 6 & 7.7 \\
Missing & .085 \\
\hline
\end{tabular}

* Percentage value is calculated based on available data.

Only a minority of students had what might be considered substantial experience with mindfulness meditation, i.e. $>50 \%$ of students had 0 to 10 hours of meditation experience, and a further $20 \%$ had accrued $<60$ lifetime hours of meditation experience (Table 2). For context, a typical regular meditator ( $\sim 30$ minutes per day) would accumulate approximately 180 hours of practice per year. 
Table 2.

Baseline Mental Health Characteristics

\begin{tabular}{lcc}
\hline Characteristic & Frequency & Percentage (\%)* \\
\hline Hours of Meditation Experience & & \\
None & 19 & 28.4 \\
$<10$ & 34 & 50.8 \\
$10-60$ & 13 & 19.4 \\
$>60$ & 1 & 1.5 \\
Missing & 4 & .056 \\
Depressive Disorder & & \\
Yes, current & 3 & 4.4 \\
In the past & 10 & 6.8 \\
Never & 55 & 80.9 \\
Missing & 3 & .042 \\
Anxiety Disorder & & \\
Yes, current & 5 & 7.4 \\
In the past & 9 & 13.2 \\
Never & 54 & 79.4 \\
Missing & 3 & .042 \\
Counseling/Psychotherapy & & \\
Yes, currently & 4 & 5.9 \\
In the past & 14 & 20.6 \\
Never & 50 & 73.5 \\
Missing & 68 & .042 \\
Psychiatric Medication & & \\
Currently taking/Have taken & 5 & 7.4 \\
Never & 63 & 92.6 \\
Missing & 3 & .042 \\
\hline
\end{tabular}

* Percentage value is calculated based on available data.

A total of 71 students completed the baseline measures; DEQ, POMS, ASI, and socio- demographic questionnaire (Table 1). The rate of selfreported anxiety and depression disorders (current or past) was $32 \%$, with $12 \%$ reporting a current clinical diagnosis of an anxiety or depressive disorder. In order to better understand factors relating to dropout, chi-square tests of independence were performed to compare baseline statistics with dropouts (at Time 2) for demographic (gender, ethnicity) and all mental health characteristics. These tests showed that there were no significant 
differences between Time 2 dropouts and non-dropouts on any demographic or mental health characteristics. Using the same dropout and non-dropout comparison, independent t-tests were conducted for psychometric scores (self-criticism, POMS tension, POMS depression, POMS fatigue, and anxiety sensitivity) at baseline, which did not result in significant differences, but showed higher mean scores on all the scales for the dropouts. This finding suggests that our speculation regarding student distress contributing to dropout risk merits further exploration and intervention, to be pursued in a future study.

Table 3:

One Way Repeated Measures ANOVA Results for Psychological Assessments of Student Meditators

\begin{tabular}{lcccc}
\hline $\begin{array}{l}\text { Psychological } \\
\text { Assessments }(\boldsymbol{n})\end{array}$ & $\bar{x}(\sigma)$ & $\mathbf{p}$-value & $\begin{array}{c}\text { Tests of Within } \\
\text { Subject Effects } \\
\text { Over Time }\end{array}$ & $\boldsymbol{\eta}_{\mathbf{p}}{ }^{2}$ \\
\hline POMS Fatigue (18) & $15.72(4.21)$ & -- & $\begin{array}{c}\mathrm{F}_{(3,51)}=45.70 \\
(\mathrm{p}<0.001)\end{array}$ & 0.729 \\
Time 1 & $14.44(4.63)$ & 0.971 & & \\
Time 2 & $6.06 *(4.30)$ & $<0.001$ & & \\
Time 3 & $7.72 * *(4.51)$ & $<0.001$ & & \\
Time 4 & & & $\mathrm{F}_{(3,51)}=24.81$ & 0.593 \\
POMS Tension- & $15.72(4.91)$ & -- & $(\mathrm{p}<0.001)$ & \\
Anxiety (18) & $15.72(5.81)$ & 1.000 & & \\
Time 1 & $5.56 * *(4.83)$ & $<0.001$ & & \\
Time 2 & $7.61 * *(5.93)$ & 0.001 & & \\
Time 3 & & & $\mathrm{F}_{(3,51)}=17.93$ & 0.514 \\
Time 4 & & & $(\mathrm{p}<0.001)$ & \\
POMS Depression & $17.00(6.77)$ & -- & \\
(18) & $15.39(8.12)$ & 1.000 & & \\
Time 1 & $4.50^{* *}(7.12)$ & $<0.001$ & & \\
Time 2 & $7.44 *(7.84)$ & 0.003 & & \\
Time 3 & & & $\mathrm{F}_{(3,51)}=69.01$ & 0.802 \\
Time 4 & & & $(\mathrm{p}<0.001)$ & \\
ASI (18) & $32.94(11.72)$ & -- & & \\
Time 1 & $31.17(10.96)$ & 1.000 & & \\
Time 2 & $16.56 * *(12.05)$ & $<0.001$ & & \\
Time 3 & $14.56^{* *}(11.38)$ & $<0.001$ & & \\
Time 4 & & & & \\
\hline
\end{tabular}


* Significant at $0.01 ; * *$ Significant at 0.001 level (Adjustment for multiple comparisons: Bonferroni)

Notes: Time 2, Time 3, and Time 4 standard means were tested using Time 1 means in pairwise comparisons for each respective scale; $\bar{x}=$ standard mean; $\eta_{\mathrm{p}}{ }^{2}=$ partial eta squared; $\sigma=$ Standard Deviation; ASI = Anxiety Sensitivity; POMS = Profile of Mood States

Table 3 displays results for one-way repeated measures ANOVAs conducted on each psychological measure to assess within-subject effects across time. All ANOVAs achieved an observed (post-hoc) power of greater than 80 percent (at the $<0.05$ level) to detect a significant difference. Pairwise comparisons were conducted for psychological outcomes at three assessment periods compared to respective baseline scores, and were adjusted for multiple comparisons with the Bonferroni correction.

Supporting our hypotheses, significant within-subject effects indicated improvements for POMS Tension-Anxiety $\left(\mathrm{F}=24.80, \mathrm{p}<0.001, \eta_{\mathrm{p}}{ }^{2}=\right.$ 0.73), POMS Depression ( $\left.F=17.93, \mathrm{p}<0.001, \eta_{\mathrm{p}}{ }^{2}=0.59\right)$, POMS Fatigue $\left(\mathrm{F}=45.70, \mathrm{p}<0.001, \eta_{\mathrm{p}}{ }^{2}=0.51\right)$, and ASI $\left(\mathrm{F}=69.01, \mathrm{p}<0.001, \eta_{\mathrm{p}}{ }^{2}=\right.$ 0.80). Pairwise comparisons did not reach significance at Time 2 indicating that by the November-December assessment, participants did not report substantial changes in mood and anxiety. However, at Time 3 and Time 4 (Figure 2) participants reported significant reductions in fatigue, tension, depression, and anxiety sensitivity. The effect sizes reflected in the $\eta_{\mathrm{p}}{ }^{2}$ estimates are all categorized as 'very strong', indicating the sample size was sufficient for the analyses undertaken (Cohen, 1988).

Correlational analyses examined the relationships between $\mathrm{SC}$ and POMS Depression Time 1 and $\Delta$ POMS Depression Time 2 (change in Depression scores at Time 2). There was a significant positive correlation between SC and POMS Depression $(r=0.46, \mathrm{p}<0.01)$, and a significant inverse correlation between SC and $\Delta$ POMS Depression Time $2(\mathrm{r}=-.32, \mathrm{p}$ $<0.05)$. These associations indicated that improvements in depressed mood were predicted by SC. POMS Depression $\Delta$ Time 2 variable was verified as normally distributed prior to regression analysis. 


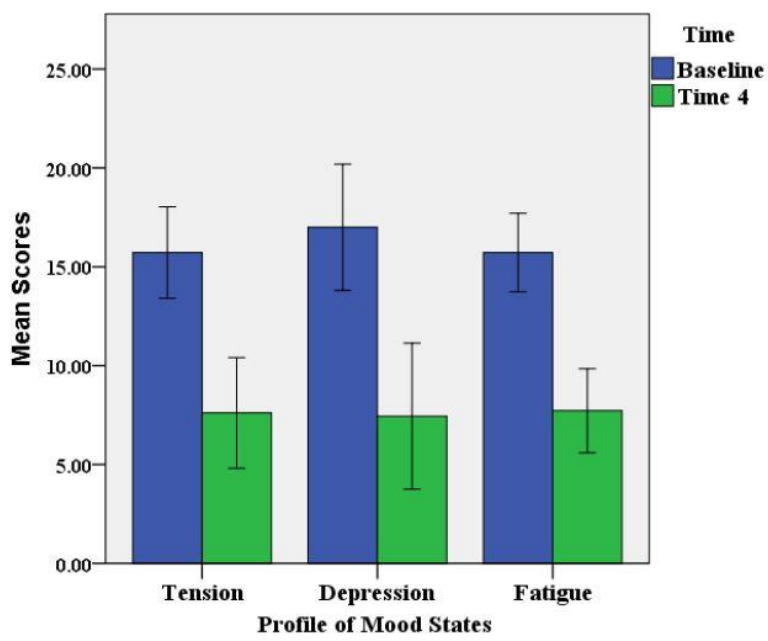

Figure 2. Changes in Profile of Mood States from Baseline to Time 4 $n=18$; T-bars indicate standard error.

As correlational analyses were conducted on available data points at Time 2, it was important to rule out the possible confounding effect of dropout on SC associations. An independent samples t-test was used to compare selfcriticism in the sub-sample who completed our MM program (completers) and all dropouts. There was no significant difference in SC scores for program completers $(\bar{x}=0.116 ; \mathrm{SD}=0.154)$ vs. non-completers $(\bar{x}=$ $0.116 ; \mathrm{SD}=0.142) ; \mathrm{t}(61)=-0.002, \mathrm{p}=0.999$.

Table 4:

Regression Analyses for Self-Criticism as Predictor of Change in Depressed Mood (POMS)

\begin{tabular}{lccl}
\hline Predictor & Unstandardized Coefficients & $\boldsymbol{\beta}$ & p-value \\
\hline Self-Criticism & $-3.19(1.42)$ & -0.35 & $<0.05$ \\
Dependency & $-0.20(1.44)$ & 0.02 & 0.89 \\
Age & $-0.20(0.11)$ & 0.29 & 0.09 \\
\hline
\end{tabular}

Notes: Outcome variable - POMS Depression $\Delta$ Time 2, Std. - Standard; $\beta=$ standardized coefficient; Model: $\mathrm{p}<0.05, \mathrm{r}=0.46, \mathrm{r} 2=0.21, \mathrm{n}=37$ 
Table 4 lists results of the regression model tested, using POMS Depression $\Delta$ at Time 2 as outcome and SC as primary predictor, with age and the Dependency subscale score as covariates. Dependency was included based on prior research strongly linking it with Self-Criticism (Mongrain \& Leather, 2006). The model was significant overall ( $\mathrm{p}<0.05$ ), and SC was found inversely related to reductions in depressed mood (i.e., higher SelfCriticism predicted greater reductions in Depressed Mood) at Time 2, accounting for $35 \%$ of variance $(\mathrm{p}<0.05)$. It was noted that the sample $(\mathrm{N}$ $=37$ ) and the analysis of 3 variables satisfied Cohen criteria of at least 10 subjects per variable (Cohen, 1988). However, the model achieved only modest observed (post-hoc) power of 58 percent (at the $<0.05$ level) to detect a significant difference.

\section{Discussion}

This study found evidence for improvements in mood disturbance and anxiety sensitivity in university students through participation in an MM program. The significant within-subjects effects observed for psychological outcomes suggest gradual improvements in response to MM exposures with changes similar to those found in prior studies of $\mathrm{MM}$ and psychological status (Oman et al., 2008; Rosenkranz et al., 2013; Tang et al., 2007). Changes in the POMS subscales Tension-Anxiety, Depression, Fatigue, and overall ASI score were significant at Time 3 (Table 3), suggesting accumulated practice was associated with progressive, significant benefits. Although significant loss of participants to attrition occurred, participants were at elevated risk for anxiety and depression, and were highly sensitive to critical thoughts (see baseline psychometric results), making them more sensitive to academic pressures and university life stressors than the general student population. Particular evidence of this stress vulnerability was found in the high drop-out levels during the Fall exam period, as students studied for exams and completed assignments critical to final grades. While the participants who remained until the end of study were sufficient in number for valid, meaningful statistical analyses, the impact of attrition on the validity of these findings for those unable to persist (with intervention and study assessments) is acknowledged. 
The use of change scores and the within-subjects design were aimed at mitigating the impact of between-subject variability. Acknowledging the need to improve retention in future research, these results are statistically sound and demonstrate meaningful improvements for participants in these domains. For these measures, scores remained improved from Time 3 to Time 4 indicating maintenance of improvements between the JanuaryFebruary and March-April measurements.

It should be noted that these improvements are particularly meaningful given the very high baseline levels of depression and distress reported by participants. At baseline, this group reported POMS subscale scores equivalent to or more distressed than depressed cancer patients (Baker, Denniston, Zabora, Polland, \& Dudley, 2002) and adults seeking psychological treatment (Norcross, Guadagnoli, \& Prochaska, 1984). Although our recruitment approach did not target individuals experiencing psychological distress, it is evident that students manifesting significant mood difficulties were drawn to the study, reiterating the alarming levels of mental health issues in universities (ACHA, 2013).Thus, it was encouraging to see that those who eventually completed the program demonstrated improvements. Results also supported the hypothesis that higher self-critical personality traits predicted greater improvements in depressed mood (Time 2).

\section{Cognitive-Emotional Changes}

Improvements in three negative subscales of the POMS were significant beginning at Time 3 and Time 4. These reductions in negative mood over time (51\% for POMS Fatigue, 50\% for POMS Tension, $74 \%$ for POMS Depression, and 56\% for Anxiety Sensitivity) (Table 3) represent significant improvements, comparable to the effects found for alternative mental health programs in universities (Regehr, Glancy, \& Pitts, 2013). These results compare favorably to prior mindfulness research using the POMS to study meditation-related mood changes in older adults undergoing an MBSR program (Young \& Baime, 2010). Prior to MBSR, participants scored 7.4 on Tension-Anxiety, 5.4 on Depression, and 7.9 on Fatigue, and after MBSR, reported mean scores of 4.6, 3.3, and 4.9 respectively (Young \& Baime, 
2010). In the present study, participants started off with much higher baseline scores of Tension-Anxiety (15.72), Depression (17.0), and Fatigue (15.72), and afterwards reported means scores of 7.61, 7.44, and 7.72 respectively (Table 3). Training in MBSR might be considered significantly more resource and cost-intensive (seated postures, walking, yoga) than the one-hour per week commitment required for our MM program. The results of our study should be understood in the context of the more flexible requirements for meditation frequency (i.e. $1 \mathrm{hr}$. practice/week).

Over time, participants who continued mindfulness practice showed evidence of improved stress adaptation, with decreasing anxiety sensitivity (ASI) scores, indicating reduced fear of physical and psychological anxiety symptoms. This result builds on previous findings indicating that MBCT is associated with reductions in anxiety sensitivity over time (Chiesa \& Serretti, 2011; Young \& Baime, 2010). As can be readily recalled, our MM instructions focused on nonjudgmental attention to breathing sensations and mind-wandering events. With continued and supported MM practice, the reactivity to anxiety-related symptoms is likely to decrease over time, explaining this marked reduction in our participants.

\section{Relationships between Self-Criticism and Depressed Mood}

As hypothesized, higher baseline self-criticism scores predicted greater reductions in depressed mood at the second assessment (end of fall term). As mindfulness meditation practice specifically builds on the ability to selfregulate and gain unbiased perspectives, individuals who were less selfcritical to begin with theoretically had less opportunity to benefit through improvements in that particular domain. Those with high levels of selfcritical tendencies evidently experienced greater MM benefits through reductions in depressed mood. This finding is notable given the lack of research on the relationship between SC traits and MM benefits. Previous research has indicated that self-reported measures of breathing awareness during meditation and trait mindfulness (comprised of stable personality variables linked to mindfulness) were associated with the capacity to neutralize depressive cognitions (Frewen, Lundberg, MacKinley, \& Wrath, 2011). The current finding between SC and the POMS Depression subscale 
suggests that negative moods linked to depressogenic self-critical traits can be modified through MM practice.

\section{Strengths \& Limitations}

This study used an informal, cost-effective, and pragmatic program to realistically assess MM benefits in a university setting, a departure from previously studied programs that were more costly and time-intensive and required more resources to implement. Our MM program was highly inclusive, efficient, and proved effective in a diverse academic population. Accordingly, this approach offers one potential model for future MM-based university programming and/or research.

While the present study did not include a control group, the effect sizes over multiple time period assessments were 'very strong,' indicating robust effects, following a within subjects design. The research demonstrating the prevalence of depression and anxiety in university students is abundant (Bayram \& Bilgel, 2008; Downs \& Eisenberg, 2012; Lynch, Gander, Kohls, Kudielka, \& Walach, 2011; Sawatzky et al., 2012; Waller et al., 2005), and the group of participants in this study can reasonably be compared to those research findings. According to prior research, depression and anxiety tend to increase over the course of the academic year (Cooke et al., 2006), making our findings of significant reductions over time a significant reversal. As participation and regular attendance in the MM program was purely voluntary, the study was prone to selection bias. But significantly distressed students were drawn to the program (as evident in baseline measures) and those who persevered and remained with the program demonstrated significant benefits. As always, self-report questionnaire data may have been influenced by social desirability biases, general adaptations to the school year, and participant expectations related to MM benefits. Lastly, the small number of program completers due to a high dropout rate must be addressed in future iterations of a program of this kind so that more students are able to maintain attendance and derive MM benefits. 


\section{Conclusion}

Our findings contribute to the growing MM literature, and to the emerging interest in disseminating mindfulness practices on university campuses for mental health benefits. In relating personality to the study of MM, the findings underline the importance of dispositional risk factors in mental illness and support the study of how mental health interventions can respond to risk-elevating traits such as self-criticism. This study also offers a model of implementing alternative, MM-based mental health programming for university students and depicts the realistic challenges involved with uptake and retention. Future investigations should explore other personality factors using a combination of psychological and neurophysiological variables to establish a more solid evidential foundation for alternative MM- based mental health programming on university campuses.

\section{Competing Interests}

The authors declare that they have no competing interests.

\section{References}

(ACHA), A. C. H. A. (2013). Reference Group Executive Summary Spring 2013. Hanover.

Baker, F., Denniston, M., Zabora, J., Polland, A., \& Dudley, W. N. (2002). A POMS short form for cancer patients: Psychometric and structural evaluation. Psycho-Oncology, 11(4), 273-281. doi:10.1002/pon.564 Bayram, N., \& Bilgel, N. (2008). The prevalence and socio-demographic correlations of depression, anxiety and stress among a group of university students. Social Psychiatry and Psychiatric Epidemiology, 43(8), 667-72. doi:10.1007/s00127-008-0345-X

Blatt, S. J., Zohar, a H., Quinlan, D. M., Zuroff, D. C., \& Mongrain, M. (1995). Subscales within the dependency factor of the Depressive Experiences Questionnaire. Journal of Personality Assessment, 64(2), 319-39. doi:10.1207/s15327752jpa6402_11 
Bourgeois, A., LeUnes, A., \& Meyers, M. (2010). Full-Scale and ShortForm of the Profile of Mood States : A Factor Analytic Comparison. Journal of Sport Behavior, 33(4), 355.

Chiesa, A., \& Serretti, A. (2011). Mindfulness based cognitive therapy for psychiatric disorders: a systematic review and meta-analysis.

Psychiatry Research, 187(3), 441-53. doi:10.1016/j.psychres.2010.08.011

Cohen, J. (1988). Statistical Power Analysis for the Behavioural Sciences. In Statistical Power Analysis for the Behavioural Sciences (Second Edi., pp. 273-407). Hillside, New Jersey: Lawrense Erlbaum Associates.

Cooke, R., Bewick, B. M., Barkham, M., Bradley, M., \& Audin, K. (2006). Measuring, monitoring and managing the psychological well-being of first year university students. British Journal of Guidance \& Counselling, 34(4), 505-517. doi:10.1080/03069880600942624 Corp., I. (2011). IBM SPSS Statistics for Windows. Armock, NY: IBM Corp.

Didonna, F. (2009a). Clinical Handbook of Mindfulness. (F. Didonna, Ed.). New York, NY: Springer New York. doi:10.1007/978-0-387-095936

Didonna, F. (Ed.). (2009b). Clinical Handbook of Mindfulness. New York, NY: Springer New York. doi:10.1007/978-0-387-09593-6

Downs, M. F., \& Eisenberg, D. (2012). Suicide and Suicide Prevention Suicidal College Students. Journal of American College Health, 60(2).

Eisenberg, D., Gollust, S. E., Golberstein, E., \& Hefner, J. L. (2007). Prevalence and correlates of depression, anxiety, and suicidality among university students. The American Journal of Orthopsychiatry, 77(4), 534-42. doi:10.1037/0002-9432.77.4.534 Erdfelder, F., Lang, E., \& Buchner, A.-G. (2007). G*Power 3: A flexible statistical power analysis program for the social, behavioural, and biomedical sciences. Behaviour Research and Therapy, 39, 175191.

Frewen, P., Lundberg, E., MacKinley, J., \& Wrath, A. (2011). Assessment of Response to Mindfulness Meditation: Meditation Breath 
Attention Scores in Association with Subjective Measures of State and Trait Mindfulness and Difficulty Letting Go of Depressive Cognition. Mindfulness, 2(4), 254-269. doi:10.1007/s12671-0110069-y

Fuhr, S., \& Shean, G. (1992). Subtypes of Depression, Efficacy, and the Depressive Experiences Questionnaire. The Journal of Psychology, 5(126), 495-506.

Grossman, P., Niemann, L., Schmidt, S., \& Walach, H. (2004). Mindfulnessbased stress reduction and health benefits. A meta-analysis. Journal of Psychosomatic Research, 57(1), 35-43. doi:10.1016/S00223999(03)00573-7

Hazlett-Stevens, H. (2012). Mindfulness-based stress reduction for comorbid anxiety and depression: case report and clinical considerations. The Journal of Nervous and Mental Disease, 200(11), 999-1003. doi:10.1097/NMD.0b013e3182718a61

Lazar, S. W., Kerr, C. E., Wasserman, R. H., Gray, J. R., Greve, D. N., Treadway, M. T., ... \& Fischl, B. (2005). Meditation experience is associated with increased cortical thickness.Neuroreport, 16(17), 1893-1897.

Lees, J., \& Davis, W. G. (2012). An Analysis of Counselling Services in Ontario Colleges Initial Report, (October).

Lynch, S., Gander, M.-L., Kohls, N., Kudielka, B., \& Walach, H. (2011). Mindfulness-based Coping with University Life: A Non-randomized Wait-list-controlled Pilot Evaluation. Stress and Health, 27(5), 365375. doi:10.1002/smi.1382

Mongrain, M., \& Leather, F. (2006). Immature Dependence and SelfCriticism Predict the Recurrence of Major Depression, 62(6), 705713. doi:10.1002/jclp

Norcross, J. C., Guadagnoli, E., \& Prochaska, J. O. (1984). Factor Structure of the Profile of Mood States (POMS): Two partial replications. Journal of Clinical Psychology, 40(5), 1270-1277.

Nyklícek, I., \& Kuijpers, K. F. (2008). Effects of mindfulness-based stress reduction intervention on psychological well-being and quality of life: is increased mindfulness indeed the mechanism? Annals of 
Behavioral Medicine: A Publication of the Society of Behavioral Medicine, 35(3), 331-40. doi:10.1007/s12160-008-9030-2

Oman, D., Shapiro, S. L., Thoresen, C. E., Plante, T. G., \& Flinders, T. (2008). Meditation Lowers Stress and Supports Forgiveness Among College Students : A Randomized Controlled Trial. Journal of American College Health, 56(5). doi:10.3200/JACH.56.5.569-578 Pirbaglou, M., Cribbie, R., Irvine, J., Radhu, N., Vora, K., \& Ritvo, P. (2013). Perfectionism, anxiety, and depressive distress: evidence for the mediating role of negative automatic thoughts and anxiety sensitivity. Journal of American College Health : $J$ of ACH, 61(8), 477-83. doi:10.1080/07448481.2013.833932

Radhu, N., Daskalakis, Z. J., Arpin-Cribbie, C. a, Irvine, J., \& Ritvo, P. (2012). Evaluating a Web-based cognitive-behavioral therapy for maladaptive perfectionism in university students. Journal of American College Health, 60(5), 357-66. doi:10.1080/07448481.2011.630703

Regehr, C., Glancy, D., \& Pitts, A. (2013). Interventions to reduce stress in university students: a review and meta-analysis. Journal of Affective Disorders, 148(1), 1-11. doi:10.1016/j.jad.2012.11.026

Reiss, S., Peterson, R. a, Gursky, D. M., \& McNally, R. J. (1986). Anxiety sensitivity, anxiety frequency and the prediction of fearfulness. Behaviour Research and Therapy, 24(1), 1-8. Retrieved from http://www.ncbi.nlm.nih.gov/pubmed/3947307

Rodriguez, B. F., Bruce, S. E., Pagano, M. A., \& Keller, S. (2004). Factor Structure of the Anxiety Sensitivity Index in Longitudinal Study of Anxiety Disorder Patients. Behaviour Research and Therapy, 42(1), 79-91.

Rosenkranz, M. a, Davidson, R. J., Maccoon, D. G., Sheridan, J. F., Kalin, N. H., \& Lutz, A. (2013). A comparison of mindfulness-based stress reduction and an active control in modulation of neurogenic inflammation. Brain, Behavior, and Immunity, 27(1), 174-84. doi:10.1016/j.bbi.2012.10.013

Sawatzky, R. G., Ratner, P. a, Richardson, C. G., Washburn, C., Sudmant, W., \& Mirwaldt, P. (2012). Stress and depression in students: the 
mediating role of stress management self-efficacy. Nursing Research, 61(1), 13-21. doi:10.1097/NNR.0b013e31823b1440 Tang, Y.-Y., Ma, Y., Wang, J., Fan, Y., Feng, S., Lu, Q., ... Posner, M. I. (2007). Short-term meditation training improves attention and selfregulation. Proceedings of the National Academy of Sciences of the United States of America, 104(43), 17152-6. doi:10.1073/pnas.0707678104

Van den Hurk, P. a M., Wingens, T., Giommi, F., Barendregt, H. P., Speckens, A. E. M., \& van Schie, H. T. (2011). On the Relationship Between the Practice of Mindfulness Meditation and Personality-an Exploratory Analysis of the Mediating Role of Mindfulness Skills. Mindfulness, 2(3), 194-200. doi:10.1007/s12671-011-0060-7

Viglione, D. J., Lovette, G. J., Gottlieb, R., \& Friedberg, R. (1995).

Depressive experiences questionnaire: an empirical exploration of the underlying theory. Journal of Personality Assessment, 65(1), 919. doi:10.1207/s15327752jpa6501_7

Waller, R., Mahmood, T., Gandi, R., Delves, S., Humphrys, N., \& Smith, D. (2005). Student mental health: how can psychiatrists better support the work of university medical centres and university counselling services? British Journal of Guidance \& Counselling, 33(1), 117128. doi:10.1080/03069880412331335876

Young, L. a., \& Baime, M. J. (2010). Mindfulness-Based Stress Reduction: Effect on Emotional Distress in Older Adults. Complementary Health Practice Review, 15(2), 59-64. doi:10.1177/1533210110387687

Muhammad Abid Azam (PhD Candidate), Myriam Mongrain (PhD), Khushboo Vora (BSc), Meysam Pirbaglou (PhD Candidate), Saam Azargive (MSc), Tina Changoor (PhD Candidate), Noah Wayne (PhD), Crissa Guglietti (PhD), Alison Macpherson $(\mathrm{PhD})$, Jane Irvine (PhD), Michael Rotondi (PhD), Dawn Smith (BSc), Daniel Perez (PhD Candidate), Paul Ritvo (PhD), at York University

Contact Address: Muhammad Abid Azam York University, 4700 Keele Street, Toronto, Ontario, M3J 1P3 